would have been happier if the publisher and/or author had added an extra 50 pages or so to what is a rather short book and included a few more details of exactly how one creates a game such as Creatures, with explicit indications of where the various notions such as self-organization and adaptation come into play in the Creatures world. But this is a minor quibble.

If you've heard about ALife but aren't quite sure what it is or where it's going, Grand's book is an excellent place to enter one of the more exciting areas of twentyfirst-century science.

John L. Casti is at the Santa Fe Institute, 1399 Hyde Park Road, Santa Fe, New Mexico 87501, USA.

\section{The man with faith in the unseeable}

Boltzmann's Atom: The Great
Debate That Launched a
Revolution in Physics
by David Lindley
Free Press: $2000.256 p p . \$ 24$
Jacqueline Reynolds and
Charles Tanford

The Zentralfriedhof on the edge of Vienna is a place of pilgrimage for many tourists. The city's largest burial ground, it has a special section, the Ehrengrüber, where Beethoven, Schubert, Brahms, Strauss and various Viennese Bürgermeister are buried. Among these luminaries lies one of the great heroes of modern-day physics, Ludwig Boltzmann. His tombstone is inscribed with the simple equation, $S=k \log W$, which may bemuse visiting music lovers but is a fitting tribute to the man who linked the phenomenological science of thermodynamics to the concept of atoms and molecules.

The true Boltzmann enthusiast (which it must be admitted includes the reviewers) would probably also visit the city of Graz, where Boltzmann spent his most productive years. There they could view the magnificent display of physical instruments he and his colleagues built for instructional purposes. Few, if any, university lecturers today would put such enormous effort into teaching after all, it is research that brings in the money.

Unfortunately, there are no definitive biographies of Boltzmann because of the scarcity of personal records about his life outside science. There is, however, a wealth of information about his scientific activities and his interactions with the worldwide scientific community. David Lindley has drawn on these latter sources to produce, not a biography of the man, but rather a biography of an idea - the debate about the

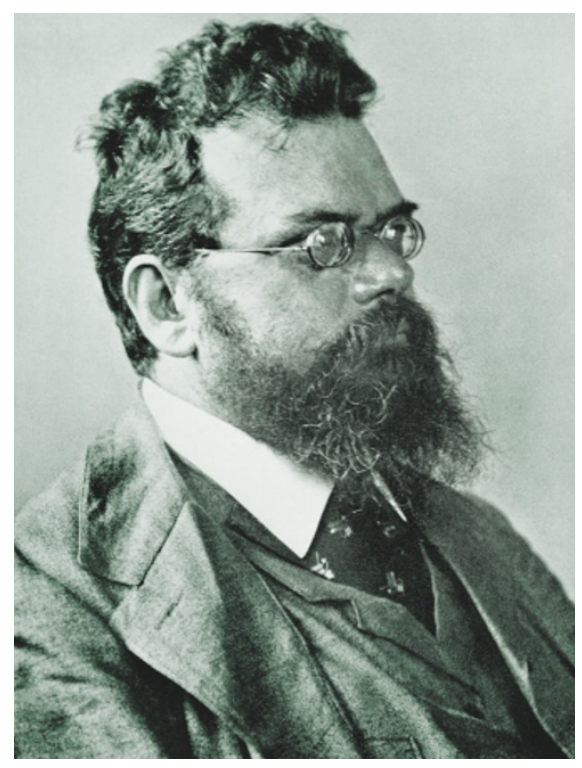

Atomic force: Boltzmann linked thermodynamics to the concept of atoms and molecules.

existence of atoms that raged in Europe in the latter years of the nineteenth century. All the familiar characters - Mach, Ostwald, Planck, Stefan, Maxwell, Einstein, Gibbs to name only a few - come alive for the reader through entertaining explanations of their work and ideas coupled to insightful glimpses of their personalities.

But the real core of this book is atomic theory as viewed by the great and the good from about 1865 to 1906, when the unfortunate (and certainly unstable) Boltzmann committed suicide. By this time, all but the most diehard of the "energeticists" had accepted the reality of atoms. The philosophical differences between those who believed in the unseen atoms and those who didn't are an important part of the story, as are the cultural differences among the adversaries. In England there was little or no resistance to atomic theory other than from the then aged and crotchety Lord Kelvin, who in 1900 is described in a letter from Josef Nabl to Stefan Meyer in Cambridge as "a silly old idiot". But in the rest of Europe, many scientists were still in thrall to a Germanic philosophy opposed to theorizing about the 'unseeable'. They believed that all physics should deal only in the realm of the observable, with ultimate truth lying in empirical laws that described such phenomena. Had Boltzmann lived in England rather than Austria, he would certainly have had an easier time.

Lindley gives a superb account of the protracted attempt to explain the second law of thermodynamics in statistical terms, first by James Maxwell and then by Boltzmann. Both men envisaged matter as consisting of atoms obeying classical Newtonian laws. The confusion engendered by Boltzmann's H-theorem, and his attempts to explain away the anomalies in its implications that others discovered, is one of the best exposés of the sub- ject we have read (albeit somewhat repetitious at times). The only slight flaw in Lindley's rendering of the debate is his failure to point out that those who opposed the statistical approach did have one reasonable objection - that classical statistical mechanics (as it came to be called by J. Willard Gibbs in 1901) could not explain the specific heats of gases. This problem had to await the advent of quantum theory in the early 1900s.

Another strange omission is from the early part of the book, in which the history of the idea of atoms is described in great detail. How can one go from the early Greeks to Maxwell's kinetic theory of gases and ignore the "father of the atom", John Dalton? Perhaps the explanation lies in the age-old antagonism between physicists and chemists: Lindley was trained in the former discipline whereas Dalton, of course, is claimed by the chemists as one of their own.

It is a great temptation to shower superlatives on a delightful account of one's favourite topic, and here we plead some personal bias. But, with that caveat, we enthusiastically recommend this book, not only to chemists and physicists, but to any scientist with an interest in the history of the subject. Perhaps that category should include us all, since we have grown up in a world firmly founded on the certainty of the chemical/physical atom.

Jacqueline Reynolds and Charles Tanford are at Tarlswood, Back Lane, Easingwold, North Yorkshire YO6 3BG, UK.

\section{For the birds}

\section{Bird Nests and Construction}

\section{Behaviour}

by Michael Hansell

Cambridge University Press: 2000. 280 pp $\$ 80, \mathfrak{E} 50$

\section{Tore Slagsvold}

For many of us, the discovery of a bird's nest when we were young created a life-long interest in birds and nature. The nest was a revelation, its rounded shape and feather lining making it a perfect bed for the eggs and a perfect cradle for the small chicks, rocking them to sleep in the soft breeze. Later, we learnt that nests were subject to natural selection, their final solution being a compromise between various demands. For example, it must be small enough to avoid detection by a predator and to fit tightly around the incubating parent, but large enough to provide space for a big brood of chicks scrambling for food. And it must be built with materials possessing good insulation properties, able to keep out moisture and to dry quickly after rain, and with the strength to stay put in the wind. 

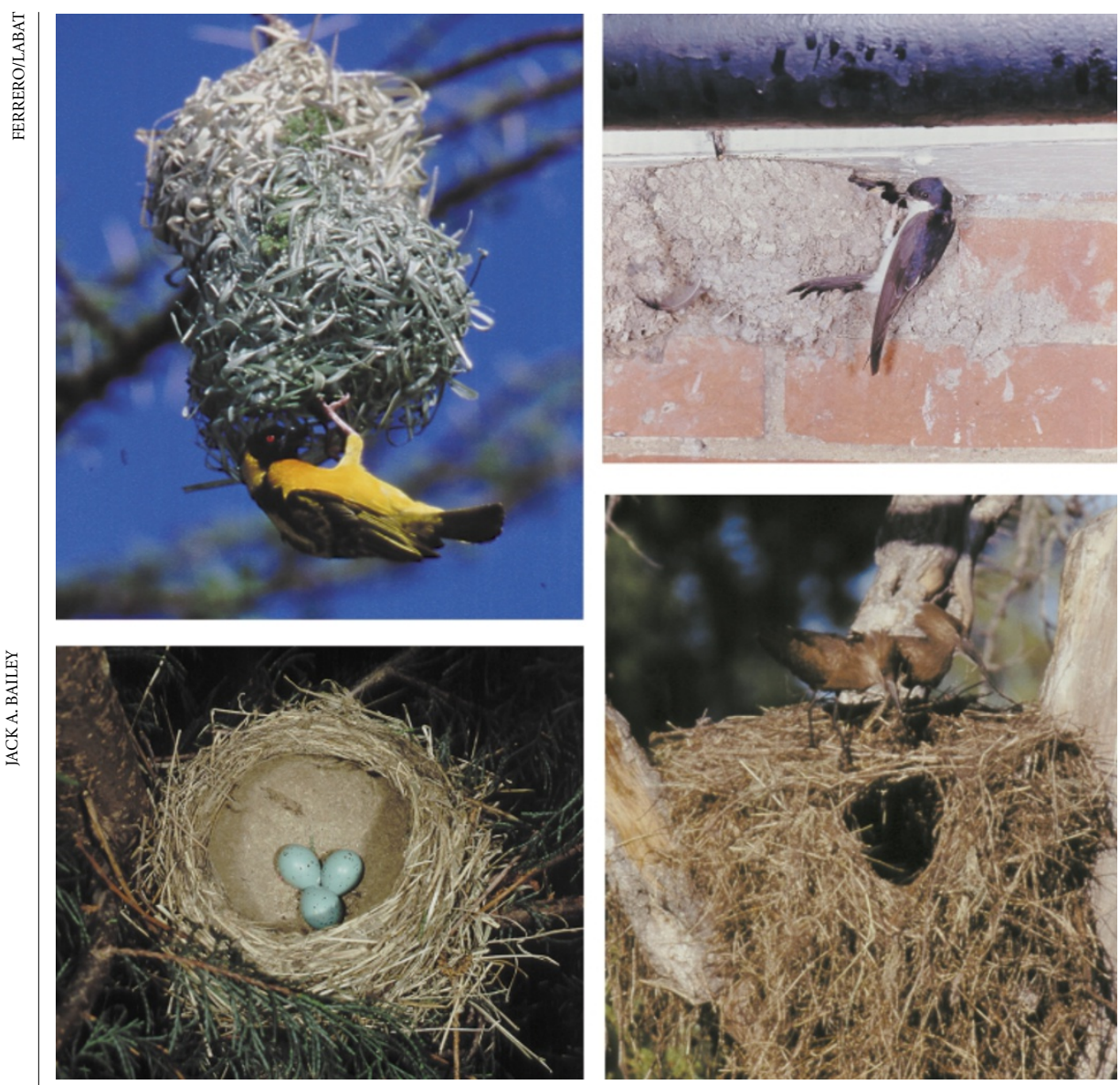

Nesting niceties (clockwise from top right): house martin, hammerkop, song thrush and village weaver.

All these aspects are included in Mike Hansell's well-written book, which provides an excellent overview. Also included are many references covering the important discoveries made since the classical books, on animal constructions, Animal Architecture and Building Behaviour (Longman) by Hansell, and on bird nests, Nest Building and Bird Behavior (Princeton University Press) by N. E. Collias and E. C. Collias, were published in 1984.

Of interest to anyone with a passion for evolutionary biology, the book describes fascinating works of engineering and architecture, ranging from how the birds' ancestors — dinosaurs - made their nests, to how a male black wheatear carries more than two kilograms of stones to impress a female.

One way to reduce the cost of nest building is to steal materials from a neighbour's nest, as many colonial birds do. Another solution is to reuse a vacated nest, although this has the drawback of a possible legacy of blood-sucking bugs. The latter problem can be alleviated, however, by the addition of green leaves possessing active agents against mites and by importing spiders to kill flies.

Hansell places all this knowledge into a framework of modern behavioural ecology, raising questions such as whether nest size is a constraint on optimal brood size, and whether selection of nest sites and nesting materials is involved in speciation. He also analyses the nests of more than 500 specimens from museum collections. His detailed categorization will probably serve as a base reference for years to come.

Is it necessary to have a big brain to build a nest? No, says Hansell. Some learning may be involved, as is seen in weavers, where experienced birds perform better than younger ones. But the great variety of sophistication of bird-nest construction is achieved with a surprisingly small repertoire of rather stereotyped behaviours and by using particular nesting materials, such as silk from insects and spiders, and vine tendrils or spiny lichens that act as 'Velcro', locking together easily.

Nest building can be likened to tool use by birds, says Hansell. Crows, which have relatively large brains, may even use narrow sticks to pick out insects during foraging. But birds are also social animals, and perhaps, as with humans, the evolution of increased brain size has been driven by complex social demands rather than by the use of tools or the construction of nests.

In any case, bird nests are beautiful and serve their purpose well. The same can also be said of this book.

Tore Slagsvold is in the Department of Biology, University of Oslo, PO Box 1050, Blindern, N-0316 Oslo, Norway.

\section{n......................... Virology in all its guises}

The Invisible Enemy: A Natural

History of Viruses

by Dorothy H. Crawford

Oxford University Press: 2000. 288 pp. $£ 14.99, \$ 25$

\section{Albert D. M. E. Osterhaus}

Dorothy Crawford's book portrays viruses as unseen enemies, with many tricks up their sleeve, and this approach leads to a fascinating story of their natural history. For the educated layperson, the book reads like a novel, despite starting with a textbook approach, explaining what a virus is and how it takes over the normal metabolism of living cells. Once the author has completed these basics, though, the book builds to a climax, describing as it develops the plethora of mechanisms by which viruses may be involved in the development of cancer.

Most of the topics dealt with, including stories of 'everyday' virus infections such as the common cold, influenza, varicella and shingles, are illustrated with real examples from medical rather than veterinary practice, a bias that reflects the author's own research interests. Of the examples, most come from Britain, showcasing the role of British pioneers in virology.

The account starts with the important contributions of Edward Jenner, who introduced the principle of vaccination. It continues with the story of Christopher Andrewes' and David Tyrrell's invaluable work at the Common Cold Unit in Salisbury and ends with Anthony Epstein, who identified the role of Epstein-Barr virus in Burkitt's lymphoma.

The darker or more controversial sides of the history of virological research are also dealt with. For example, Crawford explores the controversy between Luc Montagnier and Robert Gallo over their roles in the discovery of HIV- 1 as the cause of AIDS, and she highlights Peter Duesburg's currently untenable theory denying that HIV-1 is the sole cause of the disease. Furthermore, the so-far unsuccessful attempts to identify viral causes for other unresolved human diseases or syndromes, such as chronic fatigue syndrome, Gulf War syndrome and multiple sclerosis, present the reader with a glimpse of the challenges of modern virology.

From a historical perspective, the author explains the important role of vaccines in eliminating or eradicating viral diseases such as smallpox, polio and measles. Then, bringing the story right up to date, she discusses the increasing importance of antiviral drugs, using AIDS to illustrate the problems associated with their development and use.

The book ends by turning the tables and speculating on ways in which the invisible 